\title{
CORRESPONDENCE
}

\section{MENTAL HANDICAP}

DeAr SIR,

It is reported in the Bulletin (November, p. 190) that the average cost per patient in hospitals for the mentally handicapped in 1977 was $£ 70$ per week. In the light of proposals from the National Development Team for the Mentally Handicapped for the establishment of 'Community Units' it would be valuable to have comparative figures from such units that have now been set up. Local experience suggests that the above might at times approach the daily theoretical figure for such a unit and team; what would be the effect of the injection of this kind of money into the established NHS hospital-based services? It is coincidental that in the same issue (p. 197) Doctors Blake, Spencer and James draw attention to the entire omission of the biological aspects of mental handicap in the First report of the National Development Team?

Tom Pilkington

64 Harsley Road,
Stockton-on-Tees,

Cleveland.

\section{THE WAKEFIELD PSYCHIATRIC MUSEUM *}

\author{
Three Years Progress
}

The museum continues to attract many visitors. Psychiatrists, nurses, social workers, prison officers, students, and researchers in many fields have visited the museum, often spending many hours examining historical records. Local schools, colleges and the Open University have also made use of the facilities available. Harvard and the Massachusetts Institute of Technology have each encouraged students to visit the museum in pursuit of their specialized studies.

A museum must not remain static, and it is pleasing to record a number of new additions. Some are archival, for instance Warrants for Criminal Lunatics inscribed with the Royal Sign Manual. Through the interest of Dr A. Kerr and his colleagues at St Nicholas Hospital, Gosforth, a 'padded room' was saved from destruction and given to the museum. (It would be interesting to know if any such feature still remains elsewhere in the country.) A hydrotherapy bath has also been made available through the kindness of $\mathrm{Dr}$ Kerr. A suggestion has also been made that a full-scale working model of a 'revolving chair', in use at Wakefield in 1821 , should be constructed.
Donations of further historical material by hospitals or individuals contemplating disposal of such items would be most welcome, and the source would be acknowledged on display captions.

Copies of the booklet Stanley Royd Hospital-One Hundred and Fifty Years, production of which was made possible by the generosity of Messrs E. R. Squibb and Sons, are still obtainable, price $50 \mathrm{p}$, plus $20 \mathrm{p}$ postage and packing, from The Curator, Stanley Royd Hospital Museum, Aberford Road, Wakefield, W. Yorkshire WF1 4DQ.

The museum, entrance to which is free, is open each Wednesday 10 am to $1.0 \mathrm{pm}$, and $1.30 \mathrm{pm}$ to $4.0 \mathrm{pm}$, and may if necessary be made available at other times by special arrangements.

R. P. SNATth

- See News and Notes December 1975, p. 19, for report of opening and background information.

\section{NOTICE TO CONTRIBUTORS}

Articles submitted for consideration for publication in the Bulletin should be received at least two months prior to the date of publication. The length should not exceed 2,000 words, and two copies of the manuscript are required. 